\title{
Chorioretinal Injury Caused by Presumed Laser Dazzler
}

\section{Bruce Rivers ${ }^{1}$ and Courtney Crawford ${ }^{2 *}$}

${ }^{1}$ Winn Army Hospital, Ft Stewart GA, USA

${ }^{2}$ Blanchfield Army Hospital, Ft Campbell KY, USA

\begin{abstract}
Summary: The use of non-lethal lasers has become a vital tool for the war fighter and law enforcement community. Although deemed safe when used properly, these lasers can prove to be dangerous when used improperly. We present a 33-year-old Army soldier with decreased vision in the left eye secondary to a presumed Dazzler Laser injury.
\end{abstract}

Background: Non-lethal lasers have become a vital tool to the war fighter and law enforcement community. Although deemed safe when used properly, theses lasers can prove to be dangerous when used improperly.

Purpose: To present evidence for chorioretinal injury caused by the Laser Dazzler while in war- theater during Operation Iraqi Freedom.

Methods: The clinical presentation of the patient was documented by color fundus photographs, optical coherence tomography, Humphrey visual field 30-2, fundus autofluorescence images, and fluorescein angiograms.

Results: Exam findings three months following injury: BCVA: 20/15 OD; 20/400 OS. The Intraocular pressure was 15 $\mathrm{mmHg}$ OD. The anterior segment exam was unremarkable. The posterior segment exam revealed several chorioretinal scars involving the macula with no subretinal hemorrhage or fluid. On fluorescein angiogram, hypofluorescent lesions correspond to the chorioretinal scars. Humphrey visual field 24-2 reveals a para-central scotoma also consistent with chorioretional lesions.

Conclusion: The Laser Dazzler is a $532 \mathrm{~nm}, 500 \mathrm{~mW}$ output lasers that is potentially hazardous if used inappropriately. Military members and Law enforcement personnel need to be aware of the risks associated with the improper use of this and other laser products.

Keywords: Laser injury; Dazzler; Laser pointer; Chorioretinal scar

\section{Introduction}

The use of non-lethal handheld or weapon mounted lasers have become a vital tool to the war fighter and in law enforcement personnel as an escalation of force device. One such laser commonly used in Iraq and Afghanistan is the Laser Dazzler, which through its significant glare effect is intended to temporarily disorient its target [1]. This feature is crucial for the protection of entry control points and convoys because it offers a safe method of signaling an approaching target; interrupting the target's vision and determining if escalation to lethal force is warranted.

The Laser Dazzler produces a power output of 500 milliwatts and emits a green flashing light of wavelength $532 \mathrm{~nm}$ [1]. This laser is recommended for use at distances at or beyond 20 meters [1]. While the Laser Dazzler was developed for use on crowds, it should not be used inappropriately (ie: directed at another's eyes or used at close range) [2]. Previous reports of Laser Dazzler exposure show no retinal damage at distances of 20 meters or greater [1]. We present a case of permanent retinal damage caused by a presumed Laser Dazzler at a distance of approximately 10 meters.

\section{Case Presentation}

A 33-year-old National Guard solider presented to the Ophthalmology clinic at Madigan Army Medical Center with a complaint of decreased vision in the left eye after being lased with a Laser Dazzler three months prior, while deployed in Iraq. According to the patient, he was seated in the gunner's seat of his vehicle when an approaching fellow American soldier opened the door of the vehicle and fired the laser at his face and eyes, at a distance of less than 10 meters.
The patient immediately closed his right eye, which is the one he uses when focusing to aim at a target, but kept his left eye open

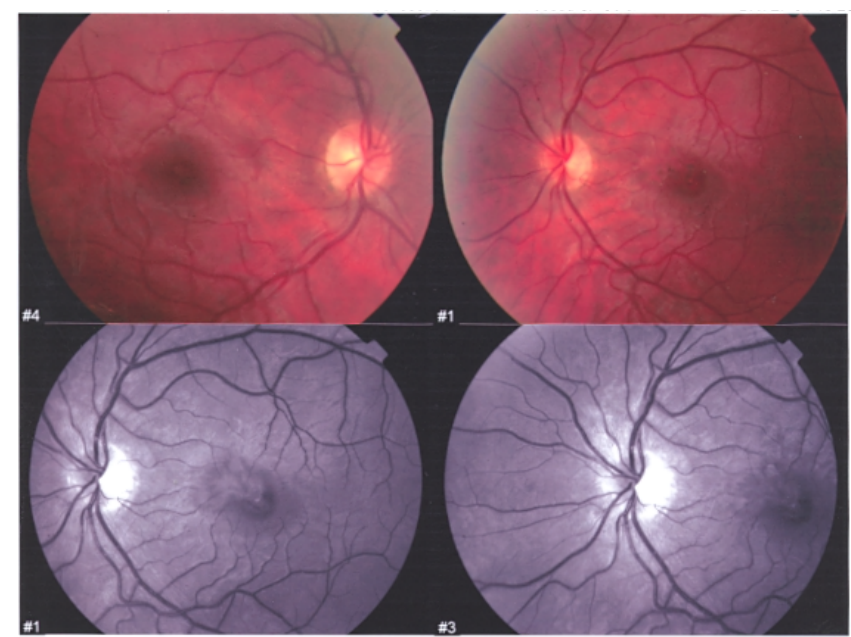

Figure 1: Color fundus photograph OS, Chorioretinal scars with RPE damage OS.

*Corresponding author: Courtney Crawford, Ophthalmology, Blanchfield Army Hospital, 650 Joel, Ft. Campbell, KY 42223, USA, Tel: 202-431-7766; E-mail: Courtney.m.crawford@us.army.mil

Received March 04, 2014; Accepted April 20, 2014; Published April 29, 2014

Citation: Rivers B, Crawford C (2014) Chorioretinal Injury Caused by Presumed Laser Dazzler. Surgery Curr Res 4: 191. doi:10.4172/2161-1076.1000191

Copyright: @ 2014 Rivers B, et al. This is an open-access article distributed under the terms of the Creative Commons Attribution License, which permits unrestricted use, distribution, and reproduction in any medium, provided the original author and source are credited. 
Citation: Rivers B, Crawford C (2014) Chorioretinal Injury Caused by Presumed Laser Dazzler. Surgery Curr Res 4: 191. doi:10.4172/21611076.1000191

in an attempt to identify the soldier in the vehicle. He then noted a green light to pass across his face and immediate decreased vision in his left eye. When the soldier who entered the vehicle and fired the laser was questioned by the battalion command, the soldier confirmed that the laser dazzler was deployed within the vehicle and was directed at the patient. The patient stated that his vision did not return to normal and over the next several days a red haze was noted when looking with his left eye. The haze resolved after a week but he continued to have decreased vision in the left eye and a blind spot in his central field of vision. Prior to the patient's MEDVAC for the war-related injury, he had an eye exam 2 weeks after the injury. Based on his deployment medical record, the visual acuity at this eye exam was reported 20/15 OD and 20/400 OS.

Upon return to the United States, three months following the injury, the patient's best-corrected visual acuity was 20/15 OD and $20 / 400$ OS. The intraocular pressures were normal. The pupils were without evidence of afferent pupillary defect. The visual fields were full to confrontation in both eyes; however, amsler grid revealed a central scotoma in the left eye. Anterior segment exam by slit lamp was normal. Dilated fundus exam revealed several chorioretinal scars involving the macula with no associated hemorrhage or subretinal fluid in the left eye (Figure 2). Fluorescein angiogram showed multiple hypoflourescent lesions and window defects that were consistent with chorioretinal scars of the left eye (Figures 3-5). Optical coherence testing revealed foveal thinning OS but no subretinal fluid. A Humphrey visual field test 30-2 performed prior to dilation revealed a paracentral scotoma in the left eye consistent with the chorioretinal scars noted on exam. The patient was followed for over one year and there was no improvement of vision, progression of chorioretinal scarring, development of subreintal fluid or signs of choroidal neovascularization were observed [3-5].

\section{Discussion}

Based on the patient's history and exam findings, we suspect that

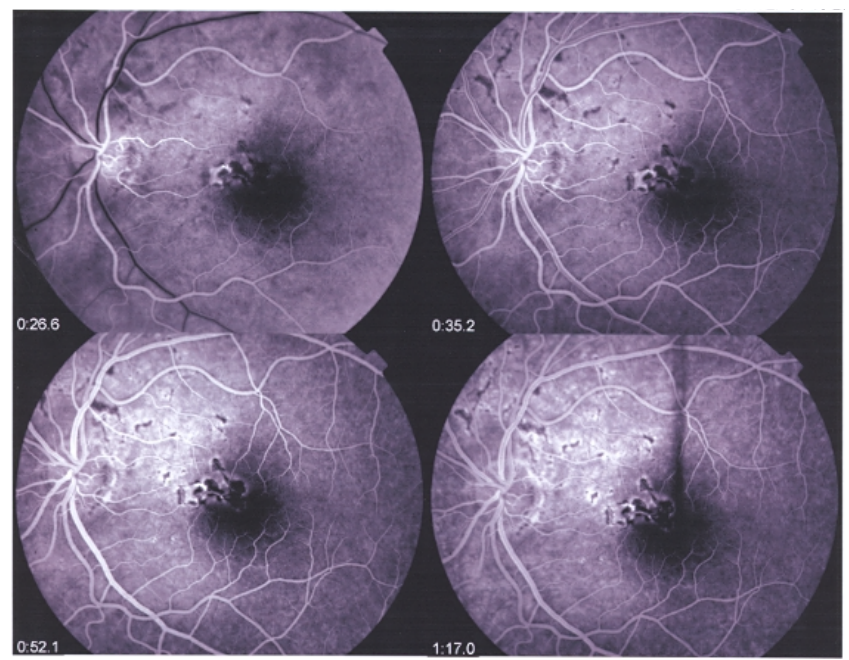

Figure 2: Ocular Coherence Tomography OS.

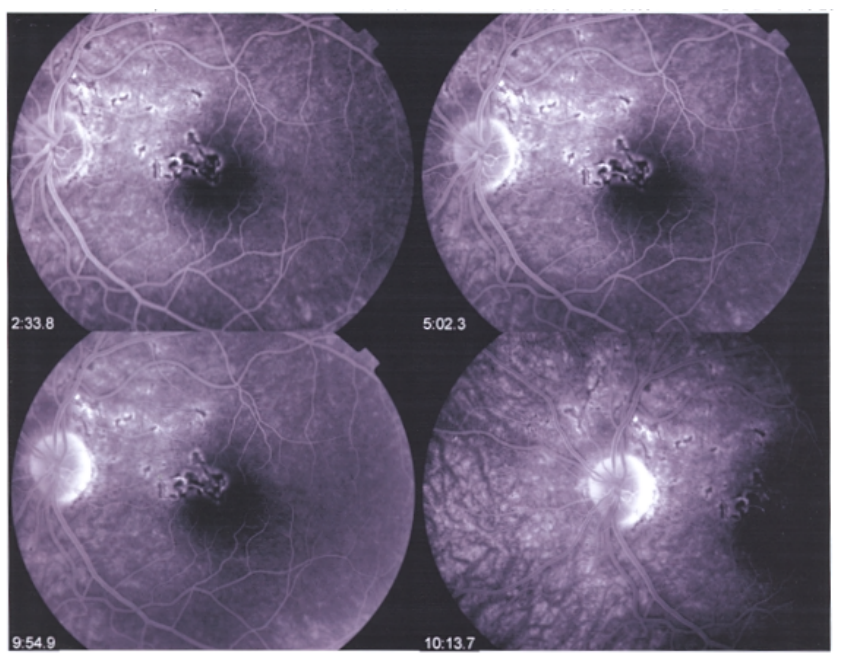

Figure 3: Fluorescein angiogram OS (45 seconds), window defects corresponding to areas of Laser Dazzler damage. 
Citation: Rivers B, Crawford C (2014) Chorioretinal Injury Caused by Presumed Laser Dazzler. Surgery Curr Res 4: 191. doi:10.4172/21611076.1000191

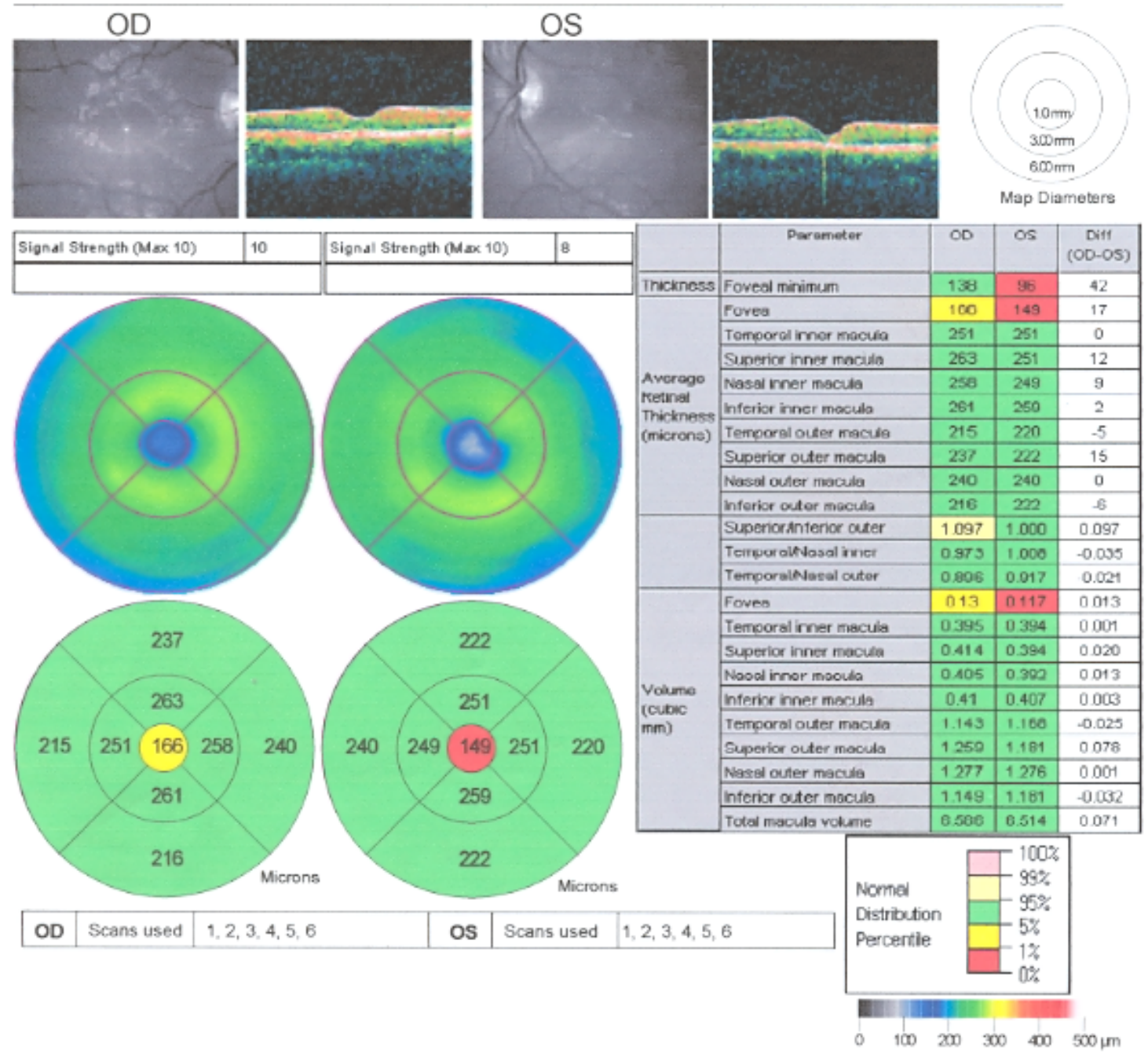

Figure 4: Fluorescein angiogram OS (45 seconds), window defects corresponding to areas of Laser Dazzler damage.

this injury was caused by a laser. Although it generally has been thought that such injuries could not be caused by the Laser Dazzler, given the patient's history of vision loss, no known prior laser treatment/injury and fluorescein pattern of deep chorioretinal scars, strong evidence supports the probable cause of a laser dazzler injury.

Laser Dazzler is a $532 \mathrm{~nm}, 500 \mathrm{~mW}$ output laser that is potentially hazardous if used inappropriately. The device projects an expanded spot rather than a collimated laser beam characteristic of most lasers used in ophthalmology. The laser output is pulsed as opposed to continuous producing a laser spot size of approximately $500 \mathrm{um}$ at 10 meters [1]. The features of discrete 500 um laser scars of the retina in our patient are consistent with the characteristics of the laser dazzler. Commercial, industrial, scientific and military laser systems can all potentially cause accidental retinal injuries $[6,7]$. As such, it is imperative that military members using any type of laser be aware of the risks associated with the improper use of the products. Health care providers should also be aware of the potential threat that some lasers may cause.

It is recommended that any patient with a suspected laser injury be examined within 24 hours of the suspected over-exposure [8]. The exam should be performed by an eye care provider and should include at a minimum: an ocular history, distance visual acuity, Amsler grid testing, a dilated fundus exam and fundus photography.

\section{References}

1. LE Systems INC (2011) Laser Dazzler. Available: http://www.laserdazzler. net/index.htm. Last accessed 21.

2. Marshall $\mathrm{J}(1998)$ The safety of laser pointers: myths and realities. $\mathrm{Br} J$ Ophthalmol 82: 1335-1338.

3. Sliney DH, Dennis JE (1994) Safety concerns about laser pointers. J Laser Appl 6: 159-164

4. Mainster MA, Timberlake GT, Warren KA, Sliney DH (1997) Pointers on laser pointers. Ophthalmology 104: 1213-1214.

5. Mainster MA (2001) Retinal laser accidents: mechanisms, management and rehabilitation. J Laser Appl 12: 3-9.

6. Mainster MA, Stuck BE, Brown J Jr (2004) Assessment of alleged retinal laser injuries. Arch Ophthalmol 122: 1210-1217.

7. Robertson DM, McLaren JW, Salomao DR, Link TP (2005) Retinopathy from a green laser pointer: a clinicopathologic study. Arch Ophthalmol 123: 629633.

8. Brown J, Hacker $\mathrm{H}$, Schuschereba ST, Zawich $\mathrm{H}$, Lund DJ, et al. (2007) Steroidal and Non-Steroidal Anti-inflammatory Medications Can Improve Photoreceptor Survival After Laser Retinal Photocoagulation. Ophthalmology 114: 1876-1883. 
Citation: Rivers B, Crawford C (2014) Chorioretinal Injury Caused by Presumed Laser Dazzler. Surgery Curr Res 4: 191. doi:10.4172/21611076.1000191

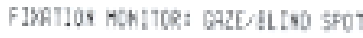

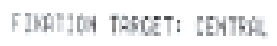

FDRTzM LOSEES: viz

FR.SE P03 Easco5; 2 :

FALSE AEG ERTCPS: $21 \%$

FEST CUEATION Q⿻上:!

คIVEA: 27 o

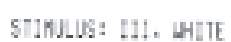
Eacrcround: 31.5 AsE

STRETECY: SITR-STANTFE:
FIPLL DIOMETER: $4.9 \mathrm{~m}$

vasual acuatT:

$9 x ;+0.2005 \quad$ or 1
thTE: at-10-2 2 at:

TIME: 解

s(E: ])

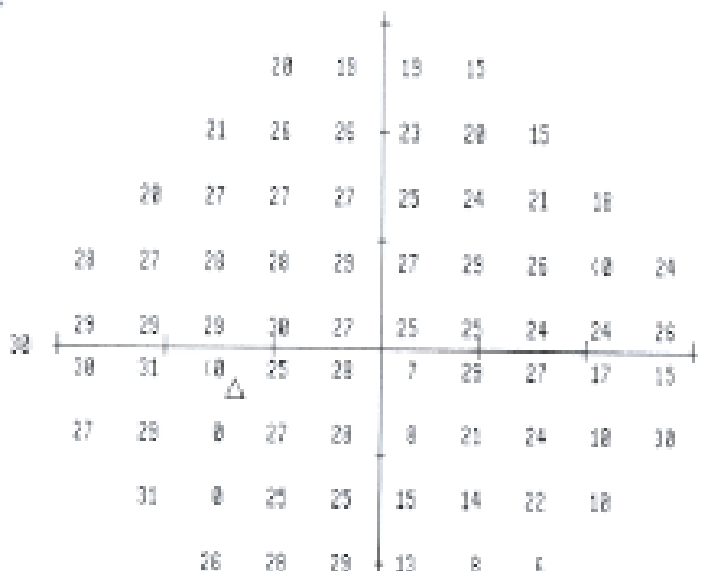

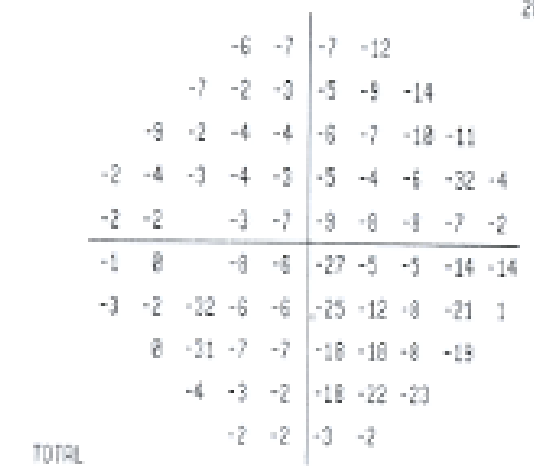

Total

JEVIRT:4

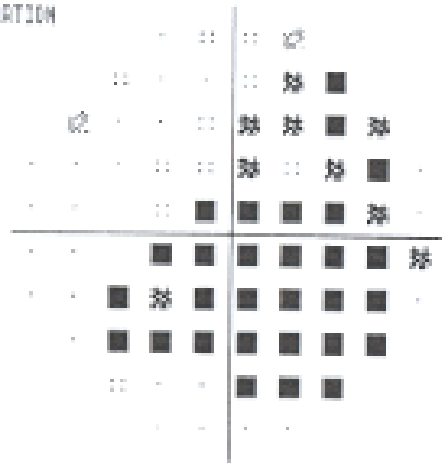

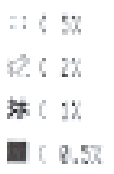

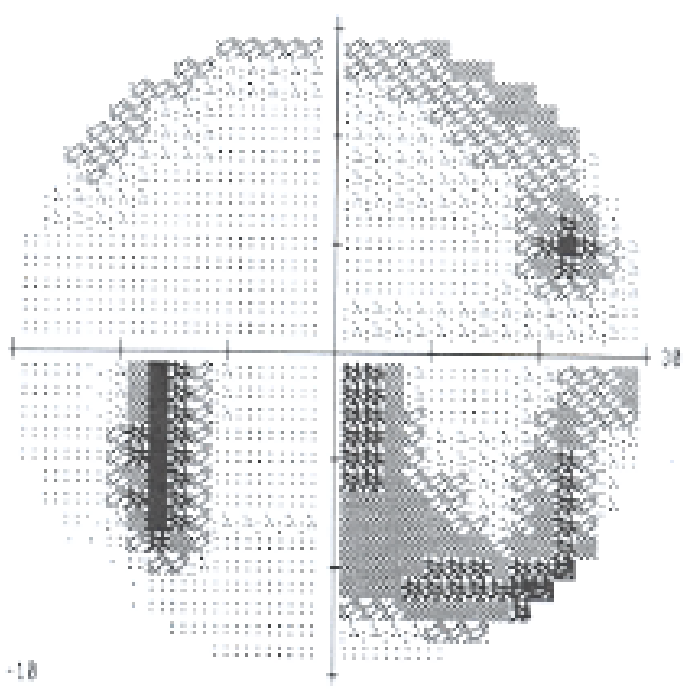

27 $\quad 26 \quad 27$

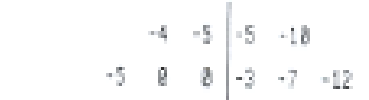

\begin{tabular}{llll|llll}
-7 & 0 & -1 & -1 & -4 & -5 & -7 & -4
\end{tabular}

$\begin{array}{llllllllll}2 & -1 & 0 & -1 & -1 & -3 & -1 & -4 & -x & -2\end{array}$

\begin{tabular}{ccccccccc}
1 & 1 & -1 & -4 & -8 & 4 & -6 & -5 & 0 \\
\hline 2 & 2 & -5 & -4 & -25 & -3 & -3 & -12 & -12
\end{tabular}

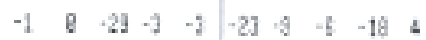

$\begin{array}{llllllll}2 & -23 & -4 & -5 & -15 & -46 & -5 & -13\end{array}$

$\begin{array}{llllll}-2 & -1 & 2 & -16 & -20 & -20\end{array}$

1 e o 1

कीT

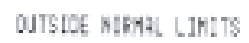

PATTER,

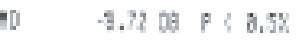

$850 \quad 8.9200 \quad p<0.2 \%$

sever:te

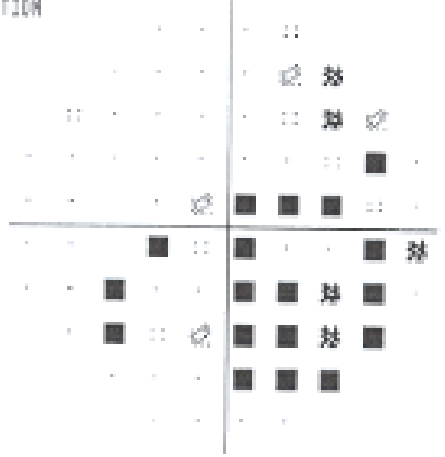

Bertha Salas, COA

MAMC Ophthalmelegy Suc

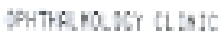

Am: U.S. जon

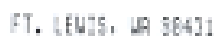

\{250\} $\$ 61 \cdot 17 \%$

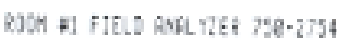

Figure 5: Fluorescein angiogram OS (45 seconds), window defects corresponding to areas of Laser Dazzler damage. 